We thank the paramedics who took part in the study. The study was supported by a grant from NHSE South West Research and Development Directorate.

Contributors: PK was the principal investigator and was responsible for project design, data collection, advice on analysis, delivery of training, and drafting the paper. $\mathrm{DH}$ was responsible for project design, data collection, liaison with paramedics, delivery of training, and drafting the paper. LP was responsible for data collection, liaison with accident and emergency departments and paramedics, and drafting the report and paper. SS was responsible for project design, monitoring and analysis of data, and drafting the paper. $\mathrm{AB}$ was responsible for project design and management, advice on analysis, and drafting the paper and is guarantor for the study. Helen Myers and Dougie Williams (Westcountry Ambulance Service) and Paul Feasby (South Devon Healthcare Trust) ensured protocol compliance; Terry Phillips (Westcountry Ambulance Service) was responsible for delivery of training; and Margaret Somerville (Teignbridge PCT) and Ken Wenman (Westcountry Ambulance Service) advised on protocol.
Funding: NHS Executive Research and Development directorate South West. The guarantor accepts full responsibility for the conduct of the study, had access to the data, and controlled the decision to publish.

Competing interests: None declared.

Boersma E, Maas ACP, Dekkers JW, Simoons MI. Early thrombolytic treatment in acute myocardial infarction: reappraisal of the Golden Hour. Lancet 1996;348:771-5.

2 Department of Health. National Service Framework for coronary heart disease: standards five to seven: heart attack, acute myocardial infarction and other acute coronary syndromes. www.nelh.nhs.uk/nsf/chd/nsf/ main/main std5_6_7.htm (accessed 17 Sep 2001).

3 Morrison LJ, Verbeek PR, McDonald AC, Sawadsky BV, Cook DJ. Mortality and prehospital thrombolysis for acute myocardial infarction. A meta-analysis. JAMA 2000:31:2686-92.

4 Royal Colleges Ambulance Liaison Committee/Ambulance Services Association. Pre-hospital thrombolysis. London: National Institute for Clinical Excellence, 2001. (Technology appraisals process series 4)

5 National Institute for Clinical Excellence. Guidance on the use of drugs for early thrombolysis in the treatment of acute myocardial infarction. London: NICE, 2002. (Technology appraisal guidance No 52)

(Accepted 23 June 2003)

\title{
Abstinence from smoking eight years after participation in randomised controlled trial of nicotine patch
}

\author{
Patricia Yudkin, Kate Hey, Sarah Roberts, Sarah Welch, Michael Murphy, Robert Walton
}

Department of Primary Health Care, University of Oxford, Institute of Health Sciences, Oxford OX3 7LF

Patricia Yudkin reader in medical statistics

Cancer Research UK General Practice Research Group, Institute of Health Sciences, Oxford OX3 7LF

Kate Hey research officer

Michael Murphy director

Sarah Roberts research nurse

Sarah Welch research nurse

Department of Clinical

Pharmacology,

University of

Oxford, Radcliffe

Infirmary, Oxford

OX2 6HE

Robert Walton

senior research fellow

Correspondence to:

P Yudkin

pat.yudkin@

dphpc.ox.ac.uk

BMJ 2003;327:28-9
Few studies have investigated abstinence beyond three years among participants who stop smoking during trials of nicotine replacement therapy, ${ }^{1-3}$ and even fewer have followed up smokers who failed to quit during such trials. We carried out an eight year follow up of people who had participated in a randomised controlled trial of the nicotine patch.

\section{Participants, methods, and results}

Participants were the 1686 patients from general practices in Oxfordshire who took part in a double blind randomised controlled trial of the patch in 1991-2.. ${ }^{4}$ At entry they smoked $\geq 15$ cigarettes a day and were aged 25-64 years. Participants wore the patches for 12 weeks. The main outcome was abstinence from smoking for one year, confirmed at 12, 24, and 52 weeks by a salivary cotinine concentration $\leq 20 \mathrm{ng} / \mathrm{ml}(89 \%$ of cases) or expired carbon monoxide $\leq 10 \mathrm{ppm}(11 \%)$.

In 1999-2000, we contacted 1532 of the 1625 living participants. We sent two follow up letters and phoned non-responders. In total 840 participants completed a questionnaire giving demographic details and information about smoking. The mean time from enrolment in the trial to follow up was 8.3 (SD 0.35) years, with a range of 7.4-9.3 years. Responders were more likely to be women $(59.0 \%$ v $51.7 \% ; \mathrm{P}=0.005)$ and were more likely to have stopped smoking during the trial than non-responders $(13.2 \% v 5.5 \%$ quit for one year; $\mathrm{P}<0.0001)$. Reported abstinence at follow up was confirmed by a plasma cotinine concentration $\leq 20$ $\mathrm{ng} / \mathrm{ml}$. Responders reported for how long they had been abstinent. We assumed that all those lost to follow up were still smoking.

Of the 153 participants who had stopped smoking for a year in the original trial, 83 were still not smoking at follow up, giving an eight year abstinence rate of
$83 / 1625$ (5\%; $95 \%$ confidence interval $4 \%$ to $6 \%)$ and a relapse rate of $70 / 153(46 \% ; 38 \%$ to $54 \%)$ (table). Relapse was similar in active and placebo groups: the active/placebo odds ratio (OR) for continuous abstinence up to follow up was 1.39 (0.89 to 2.17; $\mathrm{P}=0.19$ ) compared with 1.45 (1.04 to $2.03 ; \mathrm{P}=0.03$ ) for quitting for a year in the trial.

Of the 1472 who did not quit for a year in the trial, $116(8 \% ; 7 \%$ to $9 \%)$ were abstinent at follow up. Of these, $89(6 \% ; 5 \%$ to $7 \%)$ had abstained for a year or more, and 27 for less than a year (median 4 months). Overall at follow up therefore, $172(11 \% ; 9 \%$ to $12 \%)$ of trial participants had been abstinent for a year or more, $29(2 \%)$ had been abstinent for less than a year, and $1424(88 \%)$ were smoking.

\section{Comment}

Eight years after taking part in a randomised trial of the nicotine patch, just under half of the $9 \%$ who had stopped smoking for a year had relapsed, leaving $5 \%$ of all trial participants continuously abstinent for eight years. Previous studies have reported that a third to a half of all those who stop during a trial relapse by three or four years. ${ }^{1-3}$ Use of the nicotine patch conferred a $39 \%$ increase in the odds of continuous abstinence compared with placebo. The increase was not significant, but our original trial was not powered to detect the small difference observed in eight year abstinence rates $(5.9 \% v 4.3 \%)$. Of the majority who did not quit in the trial, only $8 \%$ had given up smoking at follow up, leaving $88 \%$ of trial participants still smoking. Our estimates were based on the conservative but well accepted assumption that those lost to follow up were still smoking. Finding more effective ways to help people to give up smoking remains an ongoing challenge. 
Estimated smoking cessation at eight year follow up among trial participants ( $n=1625)$. Values are numbers (percentage) of participants in each trial group*

\begin{tabular}{|c|c|c|c|}
\hline & Nicotine & Placebo & Total \\
\hline \multicolumn{4}{|l|}{ Followed up } \\
\hline No in group & 412 & 428 & 840 \\
\hline Quit for 1 year in trialt: & $66(16.0)$ & 45 (10.5) & $111(13.2)$ \\
\hline Abstinent from trial to 8 years & 48 & 35 & 83 \\
\hline Abstinent at 8 years for $<1$ year & 1 & 1 & 2 \\
\hline Smoking at 8 years & 17 & 9 & 26 \\
\hline Did not quit for 1 year in trial: & $346(84.0)$ & $383(89.5)$ & 729 (86.8) \\
\hline Abstinent at 8 years for $\geq 1$ year & 36 & 53 & 89 \\
\hline Abstinent at 8 years for $<1$ year & 12 & 15 & 27 \\
\hline Smoking at 8 years & 298 & 315 & 613 \\
\hline \multicolumn{4}{|l|}{ Not followed up } \\
\hline No in group & 403 & 382 & 785 \\
\hline Quit for 1 year in trial† & $25(6.2)$ & $17(4.5)$ & $42(5.4)$ \\
\hline Did not quit for 1 year in trial & $378(93.8)$ & $365(95.5)$ & $743(94.6)$ \\
\hline Assumed smoking at 8 years & 403 & 382 & 785 \\
\hline \multicolumn{4}{|l|}{ Total } \\
\hline No in group & 815 & 810 & 1625 \\
\hline Quit for 1 year in trialt: & 91 (11.2) & $62(7.7)$ & $153(9.4)$ \\
\hline Abstinent from trial to 8 years & $48(5.9)$ & $35(4.3)$ & $83(5.1)$ \\
\hline Abstinent at 8 years for $<1$ year & $1(0.1)$ & $1(0.1)$ & $2(0.1)$ \\
\hline Assumed smoking at 8 years & $42(5.1)$ & $26(3.2)$ & $68(4.2)$ \\
\hline Did not quit for 1 year in trial: & $724(88.8)$ & $748(92.3)$ & $1472(90.6)$ \\
\hline Abstinent at 8 years for $\geq 1$ year & $36(4.4)$ & $53(6.5)$ & $89(5.5)$ \\
\hline Abstinent at 8 years for $<1$ year & $12(1.5)$ & $15(1.9)$ & $27(1.7)$ \\
\hline Assumed smoking at 8 years & $676(82.9)$ & $680(84.0)$ & $1356(83.4)$ \\
\hline Total abstinent at 8 years for $\geq 1$ year & $84(10.3)$ & $88(10.9)$ & $172(10.6)$ \\
\hline Total abstinent at 8 years for $<1$ year & $13(1.6)$ & $16(2.0)$ & $29(1.8)$ \\
\hline Total assumed smoking at 8 years & $718(88.1)$ & $706(87.2)$ & $1424(87.6)$ \\
\hline
\end{tabular}

${ }^{\star}$ Table excludes the 61 trial participants known to have died since trial. All participants who were not followed up were assumed to be smoking. †Biochemically confirmed quitting at 12,24 , and 52 weeks.

We thank Lesley Jones for computing help, and Elaine Johnstone and Sian Griffiths for cotinine analysis.

Contributors: RW, PY, and MM conceived the study, wrote the protocol, and obtained funding. $\mathrm{KH}$ traced the participants and administered the study. SR and SW collected the patient data and took blood samples. PY supervised data analysis and interpretation, drafted the paper with contributions from all other authors, and is guarantor.

Funding: Cancer Research UK. The guarantor accepts full responsibility for the conduct of the study, had access to the data, and controlled the decision to publish.

Competing interests: None declared.

Ethical approval: Anglia and Oxford Multicentre Research Ethics Committee, and 86 local research ethics committees.
1 Blondal T, Gudmundsson LJ, Olafsdottir I, Gustavsson G, Westin A. Nicotine nasal spray with nicotine patch for smoking cessation: randomised trial with six year follow up. BMJ 1999;318:285-9.

2 Stapleton JA, Sutherland G, Russell MAH. How much does relapse after one year erode effectiveness of smoking cessation treatments? Long term follow up of randomised trial of nicotine nasal spray. $B M J 1998$; follow up

3 Clavel-Chapelon F, Paoletti C, Benhamou S. Smoking cessation rates 4 years after treatment by nicotine gum and acupuncture. Prev Med 1997;26:25-8

4 Imperial Cancer Research Fund General Practice Research Group. Effectiveness of a nicotine patch in helping people to stop smoking: results of a randomised trial in general practice. BMJ 1993;306:1304-8.

5 Imperial Cancer Research Fund General Practice Research Group. Randomised trial of nicotine patches in general practice: results at one year. BMJ 1994;308:1476-7.

(Accepted 6 March 2003)

\section{Smoking cessation dilemmas in prison}

Helping prisoners to stop smoking can be a real conundrum. A delicate balance has to be struck between the equality of health care that prisoners deserve and the intricacies of running a secure prison. This year I had the opportunity to view this phenomenon in one of Britain's maximum security jails.

The implementation of a workable smoking cessation programme was an uphill battle for the staff involved. Even the simplest of leaflets on giving up, kindly designed by the Health Education Board for Scotland, were unsuitable. Their suggestions to "eat more fruit" or "take a walk" in the park to beat off a craving isn't really feasible when your scenery extends only to a prison cell and your meals are what you get given, not what you request.

There were further obstacles, including the devious personalities that can be found in prisons. Nicotine replacement gum was banned because it could be used to block locks or form key impressions. Opaque patches were also disallowed for fear that they could be used to conceal small items. The influx of illicit drugs into prison excluded the use of inhalers as these could be modified for transporting other substances into the body.

There was a multitude of hurdles and unique aspects of the prison environment that had to be considered in the delivering of the smoking cessation programme. I hope that this account gives you some insight into the barriers that our colleagues in the prison health service have to contend with in the struggle to provide equality in health care for Britain's prisons.

Julie Ann Colclough University of Dundee

We welcome articles up to 600 words on topics such as A memorable patient, A paper that changed my practice, My most unfortunate mistake, or any other piece conveying instruction, pathos, or humour. If possible the article should be supplied on a disk. Permission is needed from the patient or a relative if an identifiable patient is referred to. 